\title{
BMJ Open Rehabilitation of the frail older adults in primary healthcare in rural areas: a scoping review protocol
}

\author{
Jorunn Hov (D) , ${ }^{1,2}$ Johanne Alteren, ${ }^{3}$ Kari Kvigne ${ }^{4}$
}

To cite: Hov J, Alteren J, Kvigne K. Rehabilitation of the frail older adults in primary healthcare in rural areas: a scoping review protocol. BMJ Open 2021;11:e048820. doi:10.1136/ bmjopen-2021-048820

- Prepublication history and additional supplemental material for this paper are available online. To view these files, please visit the journal online (http://dx.doi.org/10.1136/ bmjopen-2021-048820)

Received 15 January 2021 Accepted 14 May 2021

D) Check for updates

(c) Author(s) (or their employer(s)) 2021. Re-use permitted under CC BY-NC. No commercial re-use. See rights and permissions. Published by BMJ.

${ }^{1}$ Faculty of Nursing and Health Sciences, Nord University, Mo i Rana, Norway

${ }^{2}$ Faculty of Health Studies, VID Specialized UniversityHaraldsplass, Bergen, Norway ${ }^{3}$ Faculty of Health Sciences and Social Care, Molde University College, Molde, Norway

${ }^{4}$ Nursing, Høgskolen i Innlandet, Elverum, Norway

Correspondence to

Professor Johanne Alteren; johanne.alteren@himolde.no

\begin{abstract}
Introduction Frail older adults are particularly vulnerable to functional decline and adverse outcomes because they lack the necessary resistance and ability to cope. Rehabilitation services for the frail older adults are thus vital and require clarification. The aim of this review is to identify and map the scope and breadth of literature regarding rehabilitation of the frail older adults to develop a holistic rehabilitation service in primary healthcare in rural areas. The concept of rehabilitation, how rehabilitation services are organised, how patients and next of kin are involved in planning and evaluating services during rehabilitation, as well as reported results will be identified and mapped.
\end{abstract}

Methods and analysis This scoping review will be conducted based on the methodology developed by Arksey and 0'Malley. The search strategy will aim to locate both published and unpublished studies in relevant databases. Key information sources include CINAHL, MEDLINE, Embase, ProQuest and Google Scholar. Data will be extracted from papers that all three reviewers have chosen to include in the review. All three reviewers will participate in screening, assessment and selection of studies against the inclusion criteria for the review and work in teams of two. The full text of selected citations will be assessed in detail against the inclusion criteria by the same teams. Data will be extracted from papers included in the scoping review by two of the reviewers. Modifications will be detailed in the full review report. Any disagreements that arise between two reviewers will be resolved through discussion or with the third reviewer's mediation. A narrative summary of the findings will be presented accompanied by tables that reflect the objective of the review.

Ethics and dissemination Data will be obtained only from already publicly available materials. Special ethical approval is, therefore, not required.

\section{INTRODUCTION}

The complexity and breadth of the tasks is expanding the demand for capacity and competency in the municipal health and care services. The Norwegian authorities seek to promote patient-centred healthcare services where the needs of the patient must be the focal point of change and development and in the health and care services. ${ }^{1}$ A need to strengthen the rehabilitation service in the

\section{Strengths and limitations of this study}

To our knowledge, this will be the first scoping review focusing on rehabilitation of the frail older adults using primary healthcare in rural areas.

- Evidence obtained from the review will be useful for identifying any shortcomings in available studies and highlighting areas that require more research.

- The search strategy includes all languages; studies published in other than English, German and Scandinavian languages will be translated using Google Translate.

- Being a scoping review, the quality of the reviewed studies will be subject to their individual strengths and limitations.

municipalities is pointed out, but how to facilitate rehabilitation services to meet the needs of the frail older adults in a more holistic way seems to need further clarification. ${ }^{2}$

The world is facing an increasingly ageing population. Older people are more prone to diseases than younger people, frequently experiencing chronic illnesses and requiring complex healthcare. ${ }^{3}{ }^{4}$ When referring to frailty among older adults, chronic illnesses and reduced vitality in combination with the ageing process are important factors. ${ }^{356}$ Although frailty is defined in many ways, physical function, nutritional status, mental health and cognition are key aspects of the concept. Frail older adults are particularly vulnerable to functional decline and adverse outcomes because they lack the necessary resistance and ability to cope. ${ }^{37}$ The implications of this situation are important for healthcare services and may be crucial for individual welfare. ${ }^{3}$ There is a need for innovation and development of the services in keeping with the changing needs. ${ }^{1}$

Rehabilitation has many meanings depending on the particular context and culture. ${ }^{8}$ Independent of factors such as age, sex, diagnosis and geography, rehabilitation is supposed to help improve and maintain 
individuals' level of functioning. Specifically, it should assist people with self-management in activities of daily living, changing harmful lifestyles and fostering social participation. ${ }^{279}$ Associations have been found between meaning in life and physical quality of life after rehabilitation. ${ }^{10}$ Dolmer and colleagues ${ }^{8}$ have noted rehabilitation as a phenomenon connected to life-world perspectives regarding maintenance of daily functions, dignity and the dialectics between fragility and strength.

The rehabilitation process is often governed by timelimited goals. Many individuals with chronic illness(es) have follow-up needs throughout large portions of their lives, and phases of prevention, treatment and rehabilitation often overlap. ${ }^{2}$ Time-limited goals may require continuous redefinition and modification over the long term. This calls for comprehensive and coherent services. ${ }^{9}$

Different healthcare providers act as key resources for rehabilitation services. Nurses, physical therapists, vocational therapists, physicians and other healthcare providers work together in interdisciplinary settings. ${ }^{711}$ They, along with family members and other helpers, attempt to provide necessary assistance for the patient's own efforts to achieve their recovery goals, functional level, independence and social participation. Owing to the complex situation of the frail older adults, an interprofessional approach is often required for the mapping of needs, as well as implementation and evaluation of outcomes. ${ }^{9}$

Healthcare providers do not necessarily share the same approach to rehabilitation. The traditional approach in healthcare is disease oriented. ${ }^{12}{ }^{13}$ However, complex health and social needs have reduced the feasibility of disease-specific pathways in primary healthcare. Furthermore, diagnosis-independent processes are sustainable and functional. ${ }^{414} \mathrm{~A}$ more holistic approach is required. ${ }^{15}$

User (patient) involvement is a vital aspect of all forms of healthcare and very important for successful rehabilitation. Stott and Quinn ${ }^{7}$ noted that the basic aims of assisting people with disabilities are to improve, recover or limit decline in physical, mental and social skills. Further, they used an approach that emphasises identifying the aspects that the patient and their family caregivers find most relevant. This perspective is consistent with governmental guidelines expressing that the goals and resources of the person requiring care should be the starting point of rehabilitation. However, the present understanding of rehabilitation may seem narrow and poorly adapted to the goal of life mastery. ${ }^{2}$ This poses a unique challenge to the assessment and organisation of primary healthcare for meeting the individual needs of each person. Updating rehabilitation involves shifting to a new direction that focuses on increased coping, better health, safer everyday life and inclusion of the user's perspective. ${ }^{16}{ }^{17}$ An effective vision involves a healthcare service that is more person centred.

Globally, there are many district municipalities with scattered settlements, challenging infrastructure and smallscale professional environments that may be described as rural areas. However, there is regional variation of what is considered rural. ${ }^{18}$ Broadly considered as the opposite of urban, typical concepts used to define 'rural' include 'away from cities', 'low population', 'sparsely populated', 'lack of services', 'countryside' and 'nature ties'. However, there is no clear consensus about the central components of its definition. ${ }^{19}$ (pp 1-2) Climatic, geographic or demographic grounds may give rise to special challenges when comprehensive and coherent health services are needed in rural settings. The challenges may be associated with climatic extremes, distance and travel both for patients and healthcare providers, overlapping and changing roles of multidisciplinary team members and difficulties in obtaining coverage for absence and 'out-of-hours' for healthcare providers. The older adults, their friends and families and healthcare providers thus face circumstances and situations that are different from or do not occur in urban areas. Municipalities that can facilitate flexible offers or are trained in creating 'ad hoc' solutions will effectively account for recipients' current needs. In contrast, a lack of expertise and resources may cause difficulty in managing specialised and differentiated needs in small municipalities. ${ }^{20}$ In rural areas, special concerns may be connected to recruiting an adequate number of healthcare providers who command appropriate competencies. Bing-Jonsson and colleagues ${ }^{21}$ surveyed the current expertise of nursing staff against the expected competence in municipal health service. They found that nursing staff possesses competencies in the measured variables to varying degrees, but that their current skills were incompatible with the expected advanced nursing knowledge.

Scoping reviews are beneficial for mapping evidence of research, clarifying key concepts and identifying gaps in the evidence. ${ }^{22}$ An overview and assessment of the available literature on rehabilitation services of older adults in primary healthcare services in rural areas will be important for further development of the rehabilitation service.

We performed preliminary searches between August and November 2020 in PubMed, PROSPERO, MEDLINE, the Cochrane Database of Systematic Reviews and the JBI Database of Systematic Reviews and Implementation Reports to identify relevant articles. We found reviews on the topics of rehabilitation and frail older adults or primary healthcare,${ }^{23-25}$ but no reviews mapping the scope and breadth of knowledge currently available regarding rehabilitation of the frail older adults in primary healthcare in rural areas.

\section{STUDY OBJECTIVE}

The aim of this review is to identify and map the scope and breadth of literature regarding rehabilitation of the frail older adults to develop a holistic rehabilitation service in primary healthcare in rural areas.

\section{METHOD AND ANALYSIS}

O'Brien and colleagues ${ }^{26}$ claimed that a lack of consensus on terminology, definition and methodological steps 
still exists regarding scoping reviews. However, Arksey and O'Malley presented a scoping review framework in 2002. ${ }^{27}$ Their method included five stages guiding the proposed scoping interview, with an optional consultation exercise as the sixth stage. This scoping study comprises the first five stages: (1) identifying the research question; (2) identifying relevant studies; (3) selecting studies; (4) charting the data; and (5) collating, summarising and reporting the results. This framework has been further developed and improved by Levac and colleagues ${ }^{28}$ and the Joanna Briggs Institute. ${ }^{22}{ }^{29}$ The protocol is reported in accordance with the Preferred Reporting Items for Systematic Review and Meta-Analysis Protocols (PRISMA-P) 2015 statement (see online supplemental file 1$).^{22}$

\section{Stage 1: identifying the research question}

We will identify and map how the concept of rehabilitation for frail older adults is described and understood in primary healthcare in rural areas. Furthermore, we will investigate how the rehabilitation services are organised, how different participants are involved in rehabilitation and the reported results.

The study objective will be explored through these research questions:

1. How is the concept of rehabilitation for frail older adults described in primary healthcare in rural areas?

2. How are rehabilitation services organised for frail older adults in primary healthcare in rural areas?

3. What are the experiences of healthcare personnel, patients and next of kin concerning rehabilitation services in primary healthcare in rural areas?

4. How is user involvement described and implemented?

5 . What outcomes are reported?

\section{Stage 2: identifying relevant studies}

We will conduct a systematic search of CINAHL, MEDLINE via PubMed, Embase, ProQuest and Google Scholar.

The search strategy, including all identified keywords and index terms, will be adapted for each included information source. Primary research articles in peer-reviewed journals will be included. The studies can be full reports of studies using different methodologies and designs, including qualitative, quantitative and mixed methods. We will also include open grey literature addressing the research question such as governmental papers or papers from organisations, reports, theses and dissertations. The reference list of all studies selected for critical appraisal will be screened for additional literature. A health research librarian will be consulted for advice regarding the search. An initial search in MEDLINE via PubMed covering the last 10 years was performed on 30 November 2020. For a draft of the full search strategy see online supplemental file 2. We are prepared to expand the time interval depending on the number of articles and feasibility.

The systematic review will be ongoing during the autumn 2021.

\section{Stage 3: selecting studies}

The following criteria must be met for inclusion:

- Population: We want to include all adults aged $\geq 65$ years. The concept of frailty is often connected to the oldest adult age, but frailty is not an unambiguous concept. People can be frail regardless of age and the meaning of the concept may not be clearly defined. We therefore will have to consider several factors in the context such as weakness and reduced vitality in connection with the ageing process and chronic diseases in order not to miss important information/ studies about frailty and older adults. The age group of older adults may not always be specified exactly, and we consider there may be an even higher risk of selection bias if we only include the oldest adults, for example, 80 years and older.

- The core concept in this scoping review is rehabilitation. We are interested in a broader approach than disease-specific pathways, and especially experiences and outcomes with a more holistic approach to rehabilitation of frail older adults. We are searching how the services are organised as well as the user involvement in terms of how the patients and next of kin are involved in planning and evaluation of the services. We are interested in the views of healthcare workers as well as the users and their next of kin. Because we are particularly interested in rehabilitation of the frail older adults, work-oriented rehabilitation will be outside our area of interest. Neither will rehabilitation with main focus on societal benefits and economic profitability be of special interest, as we seek more holistic perspectives relevant to frail older adults and their next of kin.

- The context will be restricted to primary care settings in rural areas. Low population density and long distance to the nearest hospital are important indicators when defining an area as rural; however, different indicators may be used in different countries. ${ }^{30} 31$ Therefore, all studies using terms describing a district or community as rural or rural health services will be included to diminish the chances of excluding important findings.

We are prepared to further develop the inclusion and exclusion criteria during the screening and selection process as well as for the need to contact the authors via email for further clarifications about, for example, age group, understanding of frailty, rehabilitation and rurality in the selected studies.

Following the search, all identified citations will be collated and uploaded into EndNote V.20 or a similar software, and duplicates will be removed. Titles and abstracts will then be screened using the software Covidence. All three reviewers will participate in screening, assessment and selection of studies against the inclusion criteria for the review. Potentially relevant studies will be retrieved in full and their citation details will be imported into the Joanna Briggs Institute System for the Unified Management, Assessment and Review of Information. ${ }^{22} 32$ If only 
Table 1 Data extraction framework

\begin{tabular}{llllll}
$\begin{array}{l}\text { Authors, year, } \\
\text { country }\end{array}$ & $\begin{array}{l}\text { Participants, number } \\
\text { and settings }\end{array}$ & $\begin{array}{l}\text { Aim of the } \\
\text { study }\end{array}$ & Study design & Methodology & $\begin{array}{l}\text { Main } \\
\text { findings }\end{array}$ \\
\hline
\end{tabular}

abstracts or protocols are found in the search, we will contact the authors to inquire if a full-text article is available. The title and abstract screening will be performed by the authors in teams of two (JH-JA, JH-KK, JA-KK). The full text of selected citations will be assessed in detail against the inclusion criteria by the same teams.

Reasons for exclusion of full-text studies that do not meet the inclusion criteria will be recorded and reported in the scoping review. Any disagreements that arise between two reviewers at any stage of the study selection process will be resolved through discussion or with the third reviewer's mediation. The results of the search will be reported in full in the final review and presented in a Preferred Reporting Items for Systematic Reviews and Meta-Analyses extension for Scoping Reviews (PRISMA-ScR) flow diagram. ${ }^{33}$

\section{Stage 4: charting the data}

Data will be extracted from papers included in the scoping review by two of the reviewers. Extracted data will then be charted to include specific details about the population, concept, context, study methods and key findings relevant to the review objective. The JBI draft map table will be used as an extraction instrument and modified and revised as necessary for our purposes (see table 1). ${ }^{28} 33$ Modifications will be detailed in the full scoping review report. As in stage 3, any disagreements that arise between the reviewers will be resolved through discussion or with the third reviewer's mediation.

Besides the number of participants, also age and sex distribution and other population characteristics will be charted. Because the term frailty can be defined differently, we are interested in extracting data that overall describe the use of the concept. Descriptions of the healthcare settings-home care/nursing home, public or private sector-will be charted as well as descriptions of the rehabilitation service and the rural context. Data that directly address the five research questions will be mapped under main findings. Overall, the scoping review will provide a narrative account of findings.

\section{Stage 5: collating, summarising and reporting the results}

A narrative summary mapping the findings will be presented and accompanied by tables that reflect the objective and research questions of the review. ${ }^{25}$

\section{PATIENT AND PUBLIC INVOLVEMENT}

Neither patients nor the general public are involved in preparing this protocol. We have no plans for involving them in the final scoping review.

\section{ETHICS AND DISSEMINATION}

There are no immediate ethical conflicts because we will use published studies and public documents. Nevertheless, we will be diligent in processing the material and presenting results in accordance with the established ethical standards for research.

We anticipate that the planned scoping review will provide a comprehensive overview of the field and thus be useful for future research, specifically in terms of determining approaches for rehabilitation services for frail older adults in rural areas. The results will be disseminated as publications in peer-reviewed journals and at relevant national and international conferences.

Twitter Johanne Alteren @https://orcid.org/0000-0002-3202-5048

Contributors JH led and organised the process. All three authors (JH, JA, KK) contributed to conceptualisation, design and development of background, study objective and research questions. All authors approved the final version of the manuscript.

Funding The authors have not declared a specific grant for this research from any funding agency in the public, commercial or not-for-profit sectors.

Competing interests None declared.

Patient consent for publication Not required.

Provenance and peer review Not commissioned; externally peer reviewed.

Supplemental material This content has been supplied by the author(s). It has not been vetted by BMJ Publishing Group Limited (BMJ) and may not have been peer-reviewed. Any opinions or recommendations discussed are solely those of the author(s) and are not endorsed by BMJ. BMJ disclaims all liability and responsibility arising from any reliance placed on the content. Where the content includes any translated material, BMJ does not warrant the accuracy and reliability of the translations (including but not limited to local regulations, clinical guidelines, terminology, drug names and drug dosages), and is not responsible for any error and/or omissions arising from translation and adaptation or otherwise.

Open access This is an open access article distributed in accordance with the Creative Commons Attribution Non Commercial (CC BY-NC 4.0) license, which permits others to distribute, remix, adapt, build upon this work non-commercially, and license their derivative works on different terms, provided the original work is properly cited, appropriate credit is given, any changes made indicated, and the use is non-commercial. See: http://creativecommons.org/licenses/by-nc/4.0/.

ORCID iD

Jorunn Hov http://orcid.org/0000-0003-2440-4619

\section{REFERENCES}

1 Meld. St. 26 (2014-2015). The primary health and care services of tomorrow - localised and integrated. Report to the Storting (white paper) summary. The Norwegian Ministry of Health and care services, 2015.

2 Særtrykk til Prop. 1 S (2016 - 2017). Opptrappingsplan for habilitering og rehabilitering $(2017-2019)$. [Special printing to Prop. 1 S (2016 - 2017) Escalation plan on plan for habilitation and rehabilitation (2017 - 2019)]. Norwegian: Norwegian Ministry of Health and Care Services, 2016.

3 Wou F, Conroy S. The frailty syndrome. Medicine 2013;41:13-15.

4 Boult C, Wieland GD. Comprehensive primary care for older patients with multiple chronic conditions: "Nobody rushes you through". JAMA 2010;304:1936-43. 
5 Wallace C, Chandler L, Rogers A, et al. Caring for frail patients: best practice. Nursing Standard 2012;26:50-6.

6 Sternberg SA, Wershof Schwartz A, Karunananthan S, et al. The identification of frailty: a systematic literature review. J Am Geriatr Soc 2011;59:2129-38.

7 Stott DJ, Quinn TJ. Principles of rehabilitation of older people. Medicine 2013;41:1-4.

8 Dolmer I, Rasmussen B, Delmar C. Rehabilitering som begreb og fænomen [Rehabilitation as a concept and phenomenon]. Klin Sygepleje 2008;22:4-15.

9 Helsedirektoratet. Veileder om rehabilitering, habilitering, individuell plan og koordinator. [Norwegian Directorate of Health. Guidelines on rehabilitation, habilitation, individual plan and coordinator]. IS-2651. Norwegian: Nasjonale faglige retningslinjer, 2018.

10 Czekierda K, Zarychta K, Knoll N, et al. Links between meaning in life and physical quality of life after rehabilitation: mediating effects of positive experiences with physical exercises and mobility. PLoS One 2019;14:e0224503.

11 Ellis G, Sevdalis N. Understanding and improving multidisciplinary team working in geriatric medicine. Age Ageing 2019;48:498-505.

12 Onder G, Palmer K, Navickas R, et al. Time to face the challenge of multimorbidity. A European perspective from the joint action on chronic diseases and promoting healthy ageing across the life cycle (JA-CHRODIS). Eur J Intern Med 2015;26:157-9.

13 Aarseth T, Bachmann KE, Gjerde I. Mot samhandlingskommunen? Om endringer i kommunenes eksterne og interne relasjoner i møte med en nasjonal helsereform. [Towards the municipality of interaction? About changes in the municipalities' external and internal relations when facing a national health reform]. Nordic Organization Studies 2015;17:109-33.

14 Grimsmo A, Løhre A, Røsstad T, et al. Disease-specific clinical pathways - are they feasible in primary care? A mixed-methods study. Scand J Prim Health Care 2018;36:152-60.

15 Grimsmo A, Løhre A, Røsstad t. Helhetlige pasientforløp gjennomføring i primærhelsetjenesten. [Implementation of clinical pathways in primary care]. Tidsskrift for omsorgsforskning 2016;02:78-87.

16 Kogan AC, Wilber K, Mosqueda L. Person-Centered care for older adults with chronic conditions and functional impairment: a systematic literature review. J Am Geriatr Soc 2016;64:e1-7.

17 Meld. St. 15 (2017-2018). A full life - all your life - A Quality Reform for Older Persons. Report to the Storting (white paper). Norwegian: Norwegian Ministry of Health and Care Services, 2018.

18 De Smedt SE, Mehus G. Sykepleieforskning I rurale områder I Norge; en scoping review. Nordisk tidsskrift for helseforskning 2017;13.
19 MacGregor-Fors I, Vázquez L-B. Revisiting 'rural'. Sci Total Environ 2020;741:132789-89.

20 Tingvold L, Magnussen S. Økt spesialisering og differensiering i sykehjem. [Increased specialization and differentiation in nursing homes]. Tidsskrift for omsorgsforskning 2018;02:153-64.

21 Bing-Jonsson PC, Bjørk IT, Hofoss D, et al. Competence in advanced older people nursing: development of 'Nursing older people - Competence evaluation tool'. Int J Older People Nurs 2015;10:59-72.

22 Peters MDJ GC, Mclnerney P, Munn Z, et al. Chapter 11: Scoping Reviews (2020 version). In: Aromataris E, Munn Z, eds. JBI manual for evidence synthesis. JBI, 2020.

23 Dassah E, Aldersey H, McColl MA, et al. Factors affecting access to primary health care services for persons with disabilities in rural areas: a "best-fit" framework synthesis. Glob Health Res Policy 2018;3:36.

24 Hopman P, de Bruin SR, Forjaz MJ, et al. Effectiveness of comprehensive care programs for patients with multiple chronic conditions or frailty: a systematic literature review. Health Policy 2016;120:818-32.

25 McColl MA, Shortt S, Godwin M, et al. Models for integrating rehabilitation and primary care: a scoping study. Arch Phys Med Rehabil 2009;90:1523-31.

26 O'Brien KK, Colquhoun H, Levac D, et al. Advancing scoping study methodology: a web-based survey and consultation of perceptions on terminology, definition and methodological steps. BMC Health Serv Res 2016;16:305.

27 Arksey H, O'Malley L. Scoping studies: towards a methodological framework. Int J Soc Res Methodol 2005;8:19-32.

28 Levac D, Colquhoun H, O'Brien KK. Scoping studies: advancing the methodology. Implement Sci 2010;5:69.

29 Munn Z, Peters MDJ, Stern C, et al. Systematic review or scoping review? Guidance for authors when choosing between a systematic or scoping review approach. BMC Med Res Methodol 2018;18:143-7.

30 Wakerman J. Defining remote health. Aust $J$ Rural Health 2004;12:210-4

31 Smedt SD, Mehus G. Sykepleieforskning i rurale områder i Norge; en scoping review. [Nursing research in rural areas in Norway; a scoping review]. Nordisk tidsskrift for helseforskning 2017;13:21-42.

32 Piper C. System for the unified management, assessment, and review of information (SUMARI). Jmla 2019;107:634-6.

33 Tricco AC, Lillie E, Zarin W, et al. PRISMA extension for scoping reviews (PRISMA-ScR): checklist and explanation. Ann Intern Med 2018;169:467-73. 